\title{
MAJORIZATION INEQUALITIES RELATED TO \\ INCREASING CONVEX FUNCTIONS IN A SEMIFINITE VON NEUMANN ALGEBRA
}

\author{
TETSUO HARADA
}

\begin{abstract}
Let $\mu_{S}(x)$ denote the generalized $s$-number of an operator $x$. We show a mojorization inequality $\int_{0}^{t} \mu_{s}(f(a+b)) d s \geqslant \int_{0}^{t} \mu_{s}(f(a)+f(b)) d s$ for every increasing convex function with $f(0)=0$ and positive $\tau$-measurable operators $a, b$ affiliated with a semi-finite von Neumann algebra $\mathfrak{A}$.
\end{abstract}

Mathematics subject classification (2000): 47B15, 47A05, 15A42.

Key words and phrases: majorization, operator inequalities, singular number.

\section{REFERENCES}

[1] T. ANDO, X. ZHAN, Norm inequalities related to operator monotone functions, Math. Ann., 315 (1999), 771-780.

[2] R. BHATIA, Matrix Analysis, Springer, New York, 1996.

[3] J.C. BouRIN, Some inequalities for norms on matrices and operators, Linear Algebra Appl., 292 (1999), $139-154$.

[4] T. FACK AND H. KosAKI, Generalized s-numbers of $\tau$-measurable operators, Pacific J. Math., 23 (1986), 269-300.

[5] T. KosEM, Inequalities between $\|f(A+B)\|$ and $\|f(A)+f(B)\|$, Linear Algebra Appl., 418 (2006), 153-160.

[6] F. HiaI AND Y. NAKAMURA, Majorizations for generalized s-numbers in semifinite von Neumann algebras, Math. Z., 195 (1987), 17-27.

[7] E. Nelson, Notes on non-commutative integration, J. Funct. Anal., 15 (1974), 103-116.

[8] I. SEGAL, A non-commutative extension of abstract integration, Ann. of Math., 57 (1953), 401-457.

[9] E. STEIN AND G. WeISS, Introduction to Fourier Analysis on Euclidean Spaces, Princeton Univ. Press, 1971. 